\title{
Grid Interconnecting Solar Generation System Using Transformer Less Cascaded Seven Level Inverter
}

\author{
Naveen Kokku
}

M.Tech, Electrical and Electronics Engineering (PAID), JNTUA college of Engineering, Ananthapur, Andhra

Pradesh, India

\begin{abstract}
Multilevel inverter is a power electronic device that is used for high voltage and high power applications and has many advantages like, low switching stress, low total harmonic distortion (THD). Hence, the size and bulkiness of passive filters can be reduced. This paper proposes three topologies of a 7- level cascaded multilevel inverter with reduced number of switches with the 5-level cascaded multilevel inverter and 3-level inverter. The topologies consist of circuits with 9 switches for 7-level CMLI, 8 switches for the 5-level CMLI and 6 switches for the 3-level inverter. Apart from the reduction in switch count this paper also includes minimization of leakage currents and comparative analysis of levels of CMLI's in every inverter connected to PV source. The control scheme based on Sinusoidal Pulse Width Modulation (SPWM) is adopted due to its ease of implementation. More number of levels results in reduced THD and nearly sinusoidal output. Simulation is performed using Matlab/Simulink.
\end{abstract}

Keywords : WM (Pulse Width Modulation).Total Harmonic Distortion (THD)

\section{INTRODUCTION}

Utilization of renewable energy resources is the demand of today and the necessity of tomorrow. With advancement in power electronic technology, the solar photovoltaic energy has been recognized as an important renewable energy resource because it is clean, abundant and pollution free. The PV power supplied to the utility grid is gaining more and more visibility, while the world's power demand is Increasing [1]. Not many PV systems have so far been placed into the grid due to the Relatively high cost, compared with more traditional energy sources such as oil, gas, coal, nuclear, hydro, and wind. Solid-state inverters have been shown to be the enabling technology for putting PV systems into the grid. PV inverter, the heart of the grid connected and standalone PV system, is used to convert dc power obtained from PV modules into ac power to be fed into the grid. Improving the output waveform of the inverter reduces its respective harmonic content and hence the size of the filter used and the level of electromagnetic interference (EMI) generated by switching operation of the inverter. In recent years, multilevel inverters have become more attractive for researchers and manufacturers due to their advantages over conventional three-level pulse width-modulated (PWM) inverters. They offer improved output waveforms, smaller filter size, and lower EMI, lower total harmonic distortion (THD). 


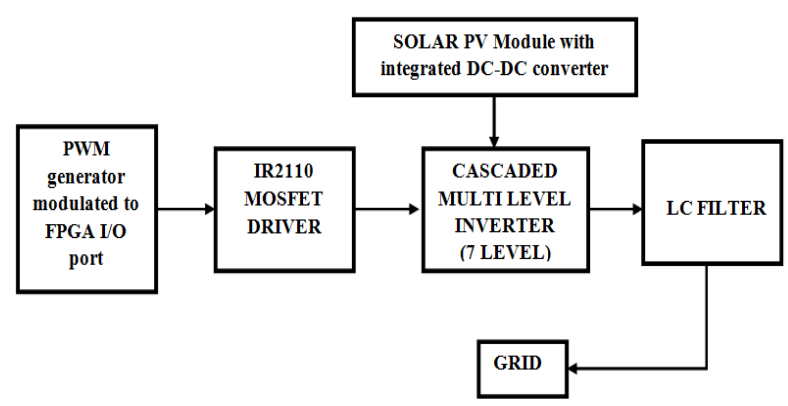

Fig 1. The basic schematic model of the standalone PV system.

Multilevel inverter are designed based on basic inverter model [4] which is shown in Fig.2 and its output is shown in Fig.3. Multilevel inverters can be used to interface with renewable energy and distributed energy resources because several batteries, fuel cells, PV cells, wind turbines, and micro turbines can be connected through a multilevel inverter to supply a load or the ac grid without voltage balancing problems [5]. Generally, the battery requires a large capacity transformer for connecting to the power system. As a result, the whole system becomes large, heavy and has low efficiency. Recently, a transformer less battery energy storage system based on a cascaded multilevel inverter has been proposed [6]. A cascaded multilevel inverter has a simple structure that has promoted its application at megavolt level.

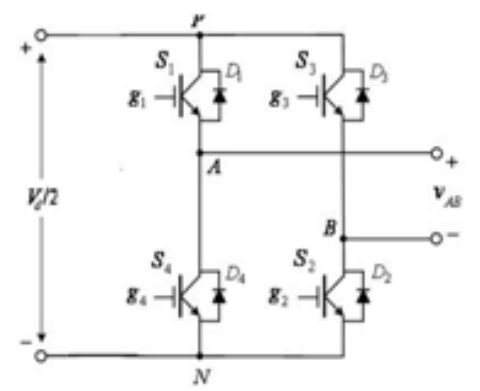

Fig.2. Basic Inverter.

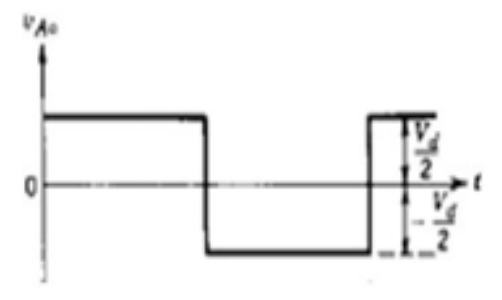

Fig.3. Output waveform.
In the case of minimisation of leakage currents there so many configurations were proposed all these configurations employ two methods for minimization of the leakage current [8]. One method is based on maintaining the common-mode voltage (CMV) constant, while the other method is based on the minimization of the high-frequency transitions in the terminal and common-mode voltages.

\section{METHODS AND MATERIAL}

\section{SEVEN LEVEL MULTI LEVEL INVERTER}

The 7-level multilevel inverter topology is introduced incorporating the least number of unidirectional switches and gate trigger circuitry, thereby ensuring the minimum switching losses, reducing size and installation cost. The new topology is well suited for drives and renewable energy applications. The performance quality in terms of THD and switching losses of the new MLI is compared with conventional cascaded MLI and other existing 7-level reduced switch topologies using carrier-based PWM techniques.

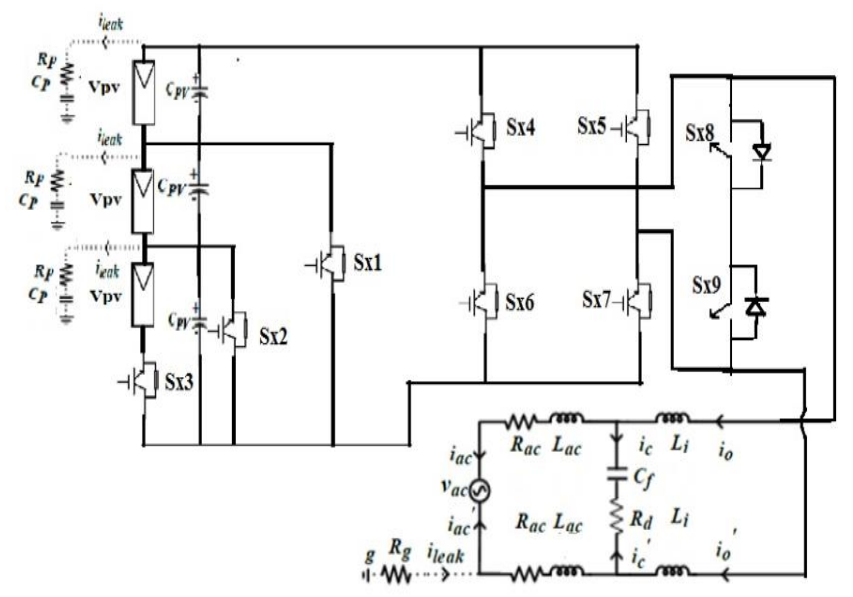

Fig 4. seven-level grid-connected CMLI with PV and parasitic elements.

Coming to the operation of seven level cascaded multilevel inverter only one switch will be 
conducting at every instant and thus making the operation very simple. For example, we get output Vpv only when Sx1 is conducting. The switching sequence for different voltage levels is shown below in the table. Each voltage source is Vpv.

\section{OPERATION OF SEVEN LEVEL CASCADED FIVE- LEVEL MLI}

The schematic circuit diagram of the proposed fivelevel CMLI for PV system is shown in Fig. 1. The given configuration consists of two converters. Converter one is a inverter comprising three switches Sx1,Sx2 and Sx3. The Converter2 comprises of a highly efficient and reliable inverter configuration [15] with six switches (Sx4 to Sx9). Among the six switches, four switches (Sx4 to $\mathrm{Sx} 7)$ in Converter 2 constitute an $\mathrm{H}$-bridge circuit.

The remaining two switches $\mathrm{Sx} 8$ and $\mathrm{Sx} 9$ in Converter-2 are bi-directional switches. The switches in the Converter- 1 are used to generate the voltage levels of $3 \mathrm{Vpv}, 2 \mathrm{Vpv}$ and $\mathrm{Vpv}$. When switch Sx1 is turned $\mathrm{ON}$, the voltage $\mathrm{Vpv}$ is applied at the terminals of output and when switch Sx2 ON the output voltage attains $2 \mathrm{Vpv}$ Similarly, the terminals of output attains the voltage $3 \mathrm{Vpv}$ when switch $\mathrm{Sx} 3$ is turned ON. The switches $\mathrm{Sx} 1, \mathrm{Sx} 2$ and $\mathrm{Sx} 3$ are complementary in nature. The generated voltage levels at the terminal $\mathrm{n}$ of Converter 1 are given as an input to the Converter2.

The Converter- 2 generates the positive, negative and zero levels of corresponding input voltage of the converter-2 to the load. The bi-directional switches Sx8 and Sx9 provide the free-wheeling path during zero voltage state. The output of the seven-level CMLI is connected to the grid through an LCL filter as shown in Fig. 1. It consists of inverter side inductance $\mathrm{Li}$, capacitance $\mathrm{Cf}$ and grid side inductance Lac.
The resistance Rd in the shunt branch of the filter is used as a damping resistor. The resistance Rac refers to the grid side resistance, and the resistance $\mathrm{Rg}$ indicates resistance in the ground path. The variable vac refers to instantaneous grid voltage. The variables $\mathrm{Rp}$ and $\mathrm{Cp}$ refer to the parasitic resistance and capacitance in the PV system, respectively shown with dotted lines.

The switching operation of the seven level CMLI is shown in the table.

\begin{tabular}{|c|c|c|c|c|c|c|c|c|c|}
\hline Sxl & Sx2 & $\mathrm{Sx3}$ & $\mathrm{Sx} 4$ & Sx5 & Sx6 & Sx7 & Sx8 & Sx9 & Output Voltage \\
\hline 1 & 0 & 0 & 1 & 0 & 0 & 1 & 1 & 0 & + Vpv \\
\hline 0 & 1 & 0 & 1 & 0 & 0 & 1 & 1 & 0 & $+2 \mathrm{Vpv}$ \\
\hline 0 & 0 & 1 & 1 & 0 & 0 & 1 & 1 & 0 & $+3 \mathrm{Vpv}$ \\
\hline 1 & 0 & 0 & 0 & 0 & 0 & 0 & 1 & 0 & 0 \\
\hline 0 & 1 & 0 & 0 & 0 & 0 & 0 & l & 0 & 0 \\
\hline 0 & 0 & 1 & 0 & 0 & 0 & 0 & 0 & 1 & 0 \\
\hline 1 & 0 & 0 & 0 & 1 & 1 & 0 & 0 & 1 & -Vpv \\
\hline 0 & 1 & 0 & 0 & 1 & 1 & 0 & 0 & 1 & $-2 \mathrm{Vpv}$ \\
\hline 0 & 0 & 1 & 0 & 1 & 1 & 0 & 0 & 1 & $-3 \mathrm{Vpv}$ \\
\hline
\end{tabular}

Table 1. switching states for 7- level CMLI with their respective output voltage

From the table 1 . The output voltage of the 7- level CMLI getting as +/- 3PV, +/- 2PV, +/-PV. These output can be expressed in terms of equations as

$$
\begin{array}{r}
\mathrm{V} 1=S x 3(S \times 4 * S \times 7-S x 5 * S \times 6)(3 V p v) \ldots(1) \\
V 2=S x 2(S \times 4 * S x 7-S x 5 * S \times 6)(2 V p v) \ldots . .(2) \\
V 3=S x 1(S \times 4 * S x 7-S x 5 * S \times 6)(V p v) \ldots . .(3)
\end{array}
$$

And the resultant output voltage

$$
\mathrm{V}=\mathrm{V} 1+\mathrm{V} 2+\mathrm{V} 3
$$

From (1),(2) and (3)

$$
\begin{gathered}
\mathbf{V}=(\mathrm{Sx} 3)(\mathrm{Sx} 4 * \mathrm{Sx} 7-\mathrm{Sx} 5 * \mathrm{Sx6})(3 \mathrm{Vpv}) \\
+ \\
(\mathrm{Sx} 2)(\mathrm{Sx} 4 * \mathrm{Sx} 7-\mathrm{Sx} 5 * \mathrm{Sx6})(2 \mathrm{Vpv}) \\
+
\end{gathered}
$$


$(\mathrm{Sx1})(\mathrm{Sx} 4 * \mathrm{Sx} 7-\mathrm{Sx} 5 * \mathrm{Sx} 6)(\mathrm{Vpv})$

From equation (4),

Whenever Sx4,Sx7 were ON and if Sx3 ON +3Vpv as output voltage, if $\mathrm{Sx} 2 \mathrm{ON}+2 \mathrm{Vpv}$ and if $\mathrm{Sx} 1 \mathrm{ON}+\mathrm{Vpv}$ as output voltages.

Similarly,

whenever Sx5,Sx6 ON and if Sx3 ON -3Vpv as output voltage, if $\mathrm{Sx} 2 \mathrm{ON}-2 \mathrm{Vpv}$ and if $\mathrm{Sx} 1 \mathrm{ON}-\mathrm{Vpv}$ as output voltages.

Coming to the minimization of leakage current in the cascaded seven level multi level inverter is achieve by making common mode voltage of the cascaded multi level inverter constant.

\section{5-LEVEL CASCADED MULTI LEVEL INVERTER}

The generalized topology for $2 \mathrm{~m}+1$ levels can also be obtained for the proposed five-level CMLI. The number of PV sources in CMLI is denoted by the term $\mathrm{m}$. The value of $\mathrm{m}$ is always an integral multiple of 2 (i.e., $\mathrm{m}=2,4 \ldots$ ). The extended version of the proposed CMLI for $2 \mathrm{~m}+1$ levels is presented in Fig. 4 . The generalized topology is obtained by cascading the basic units consisting of half-bridge and $\mathrm{H}$-bridge. The bi-directional switches are connected in between the output terminals for the free-wheeling period.

The schematic circuit diagram of the proposed fivelevel CMLI for PV system is shown in Fig. 1. The given configuration consists of two converters (Conv1 and Conv-2).Conv-1 is a half-bridge inverter comprising two switches Sx1 and Sx2. The Conv-2 comprises of a highly efficient and reliable inverter configuration [15] with six switches (Sx3 to Sx8).

The schematic circuit diagram of the proposed fivelevel CMLI for PV system is shown in Fig. 1. The given configuration consists of two converters (Conv1 and Conv-2).Conv-1 is a half-bridge inverter comprising two switches Sx1 and Sx2. The Conv-2 comprises of a highly efficient and reliable inverter configuration [15] with six switches (Sx3 to Sx8).

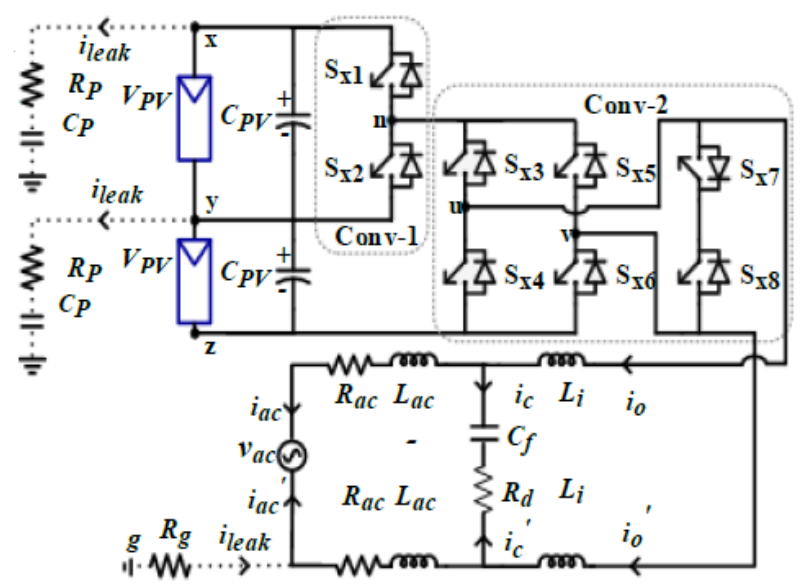

Fig.5. five-level grid-connected CMLI with PV and parasitic elements.

Among the six switches, four switches (Sx3 to Sx6) in Conv-2 constitute an H-bridge circuit. The remaining two switches $\mathrm{Sx} 7$ and $\mathrm{Sx} 8$ in Conv-2 are bidirectional switches. The switches in the Conv-1 are used to generate the voltage levels of $\mathrm{Vpv}$ and $\mathrm{Vpv} / 2$. When switch $\mathrm{Sx} 1$ is turned $\mathrm{ON}$, the voltage $\mathrm{Vpv}$ is applied at the terminal $\mathrm{n}$ with respect to the terminal z. Similarly, the terminal $\mathrm{n}$ attains the voltage $\mathrm{Vpv} / 2$ when switch Sx2 is turned ON.

The switches Sx1 and Sx2 are complementary in nature. The generated voltage levels at the terminal $n$ of Conv-1 are given as an input to the Conv-2. The Conv-2 generates the positive, negative and zero levels of corresponding input voltage (voltage between the terminals $\mathrm{n}$ and $\mathrm{z}$ ) across the load.

\begin{tabular}{ccccccccc}
\hline \hline $\mathrm{S}_{\mathrm{xl}}$ & $\mathrm{S}_{\mathbf{x} 2}$ & $\mathrm{~S}_{\mathbf{x} 3}$ & $\mathrm{~S}_{\mathbf{x} 4}$ & $\mathrm{~S}_{\mathbf{x} 5}$ & $\mathrm{~S}_{\mathbf{x} 6}$ & $\mathrm{~S}_{\mathbf{x} 7}$ & $\mathrm{~S}_{\mathbf{x} 8}$ & Vout \\
\hline 1 & 0 & 1 & 0 & 0 & 1 & 1 & 0 & $+\mathbf{2 V p v}$ \\
0 & 1 & 1 & 0 & 0 & 1 & 1 & 0 & $+\mathbf{V p v}$ \\
0 & 1 & 0 & 0 & 0 & 0 & 1 & 0 & 0 \\
1 & 0 & 0 & 0 & 0 & 0 & 1 & 0 & 0 \\
0 & 1 & 0 & 1 & 1 & 0 & 0 & 1 & $-\mathbf{V p v}$ \\
1 & 0 & 0 & 1 & 1 & 0 & 0 & 1 & $-\mathbf{2 V P V}$ \\
\hline \hline
\end{tabular}


Table 2. switching states for 5- level CMLI with their respective output voltage

The cascaded multilevel inverter uses set of series connected full-bridge inverters with separate DC sources in a modular setup to create the stepped waveform. A full bridge inverter is in itself a 3 level cascaded multilevel inverter and every module added in cascade to that extends the inverter with two more voltage levels, which then increases the number of steps in the waveform. The traditional two or three levels inverter does not completely eliminate the unwanted harmonics in the output Waveform. Therefore, using the multilevel inverter as an alternative to traditional PWM inverters is investigated.

From the table 2. The output voltage of the 7- level CMLI getting as $+/-2 \mathrm{PV},+/-\mathrm{PV}$. These output can be expressed in terms of equations as

$$
\begin{gathered}
\mathrm{V} 1=\operatorname{Sx1}(\mathrm{Sx} 3 * \mathrm{Sx6}-\mathrm{Sx} 4 * S \times 5)(2 \mathrm{Vpv}) \\
\mathrm{V} 2=\mathrm{Sx2}(\mathrm{Sx3} * \mathrm{Sx6}-\mathrm{Sx} 4 * S \times 5)(\mathrm{Vpv})
\end{gathered}
$$

And the resultant output voltage

$$
\mathrm{V}=\mathrm{V} 1+\mathrm{V} 2
$$

From (5),(6)

$$
\begin{gathered}
\mathrm{V}=\mathrm{S} \times 1(\mathrm{~S} \times 3 * S \times 6-S \times 4 * S \times 5)(2 \mathrm{Vpv}) \\
+ \\
\mathrm{Sx2}(\mathrm{Sx3} * \mathrm{Sx6}-\mathrm{Sx4} * \mathrm{Sx} 5)(\mathrm{Vpv})
\end{gathered}
$$

From equation (7),

Whenever Sx3,Sx6 were ON and if Sx1 ON +2Vpv as output voltage and if $\mathrm{Sx} 2 \mathrm{ON}+\mathrm{Vpv}$ as output voltages.

Similarly, whenever Sx4,Sx5 were ON and if Sx1 ON $-2 \mathrm{Vpv}$ as output voltage and if $\mathrm{Sx} 2 \mathrm{ON}-\mathrm{Vpv}$ as output voltages.

\section{3-LEVEL INVERTER}

The 3 level inverter is like the basic full bridge inverter, having the pulses from the PWM technique. The pulses were generated as per the output requirement. The inverter connected to grid from the PV source. PV source gives constant DC to the inverter and inverter converts $\mathrm{DC}$ to $\mathrm{AC}$ and connected to grid. The basic circuit diagram for the 3 level inverter connected to the grid from the PV source. The switching operations for the 3 level inverter is given in the table 3 . There are 6 switches in 3-level inverter. The two switches $(\mathrm{S} x 1, \mathrm{~S} x 4)$ operated at one instant i.e. for positive output and another two switches $(\mathrm{Sx} 2, \mathrm{Sx} 3)$ operate for the negative output. The bi-directional switches Sx5 and Sx6 provide the free-wheeling path during zero voltage state.

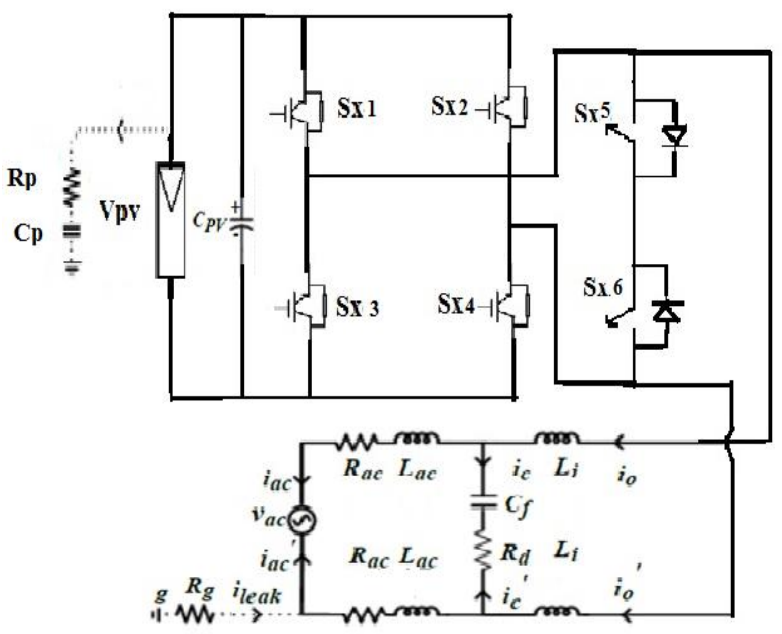

Fig. 6. Three-level grid-connected Inverter with PV and parasitic elements. 


\begin{tabular}{|c|c|c|c|c|c|c|}
\hline Sx1 & Sx2 & Sx3 & Sx4 & Sx5 & Sx6 & $\begin{array}{c}\text { Output } \\
\text { voltage }\end{array}$ \\
\hline 1 & 0 & 0 & 1 & 1 & 0 & $+\mathrm{Vpv}$ \\
\hline 0 & 0 & 0 & 0 & 1 & 0 & 0 \\
\hline 0 & 0 & 0 & 0 & 0 & 1 & 0 \\
\hline 0 & 1 & 1 & 0 & 0 & 1 & $-\mathrm{Vpv}$ \\
\hline
\end{tabular}

Table 3. switching states for 3 level inverter with their respective output voltage.

From the table 3 . The output voltage of the 3- level CMLI getting as +/-PV. These output can be expressed in terms of equations as

$$
\begin{aligned}
& \mathrm{V} 1=\mathrm{Sx} 1 * \mathrm{Sx} 4 \\
& \mathrm{~V} 2=\mathrm{Sx} 2 * \mathrm{Sx} 3
\end{aligned}
$$

And the resultant output voltage

$$
\mathrm{V}=\mathrm{V} 1+\mathrm{V} 2
$$

From (8),(9)

$$
\mathrm{V}=\mathrm{Sx} 1 * \mathrm{Sx} 4-\mathrm{Sx} 2 * \mathrm{Sx} 3
$$

Whenever Sx1,Sx4 were ON +Vpv as output voltages. Similarly,

Whenever Sx2,Sx3 were ON, - Vpv as output voltages.

\section{SIMULATION RESULTS}

The simulation results includes comparison of the three different inverters connected by PV panels and supplied to grid. It also consists comparison of the three different inverters with their levels of output, leakage current and THD of the grid current by using MATLAB/SIMULINK software.

\section{Cascaded Seven level Inverter}

The simulation model of Reduced Switches Cascaded 7- level MLI of designed using MATLAB/SIMULINK
Software. The gating signals for the inverter are generated by using multicarrier modulation technique. The circuit was simulated with grid connected to CMLI., Here in this section simulation results and observations of Photovoltaic Application based 7- level Cascaded MLI with Reduced No. of Switches is presented. The different parameters (like voltage, current, THD) are observed.

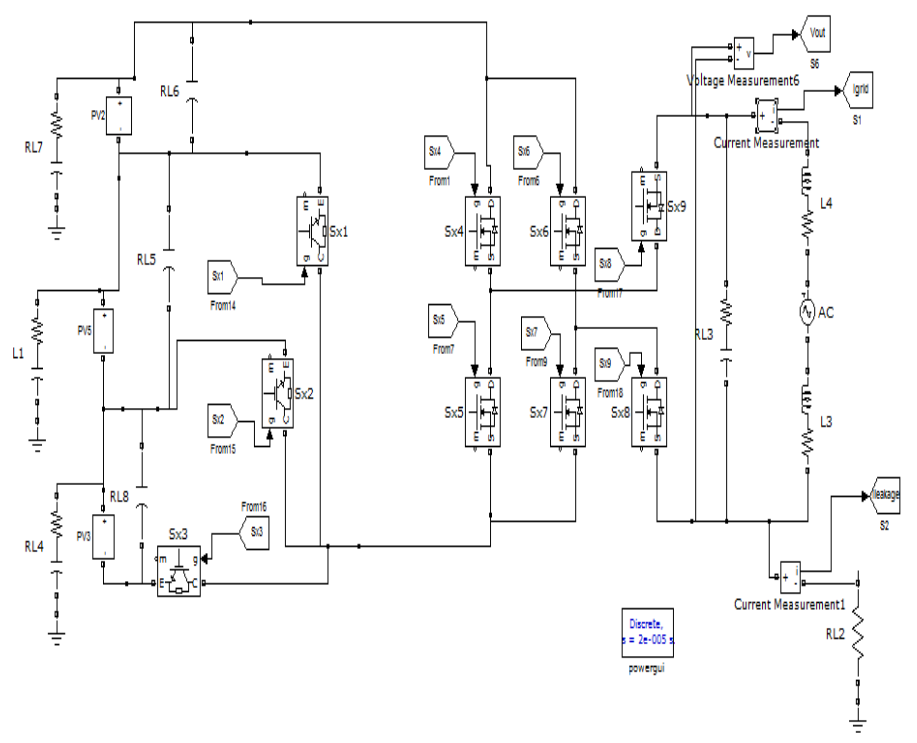

Fig 7. MATLAB Model of Photovoltaic based 7- level Cascaded MLI with reduced no. of switches.
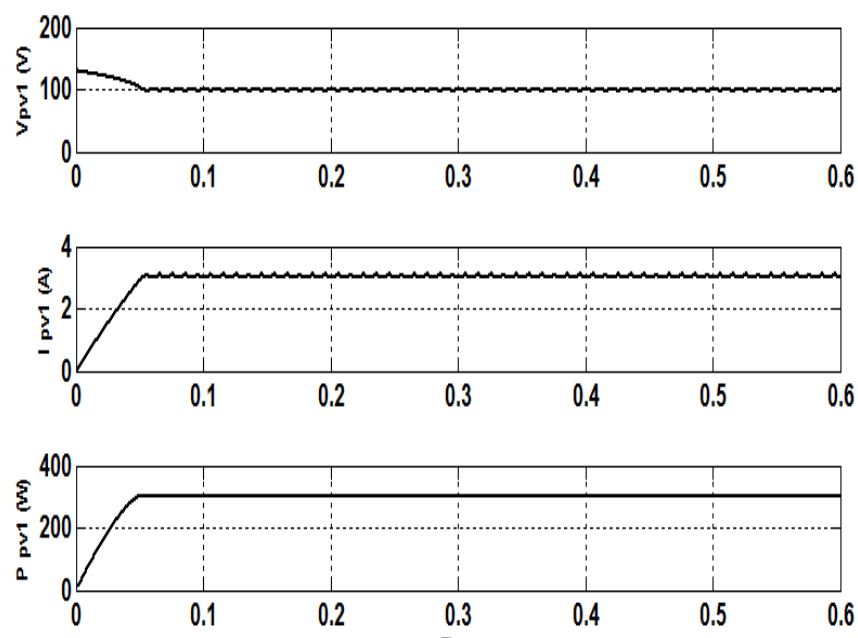

Fig 8. Simulation waveforms of the PV Panel 1 Voltage (V), Current (A), and Power (W). 

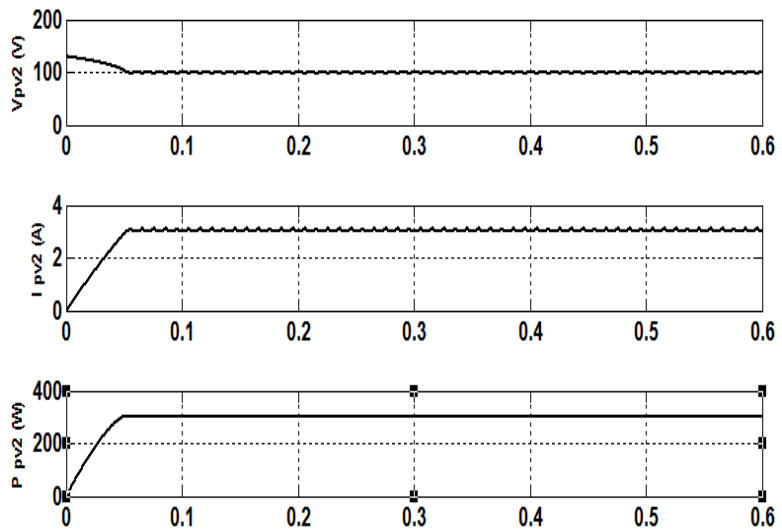

Fig 9. Simulation waveforms of the PV Panel 2 Voltage (V), Current (A), and Power (W).
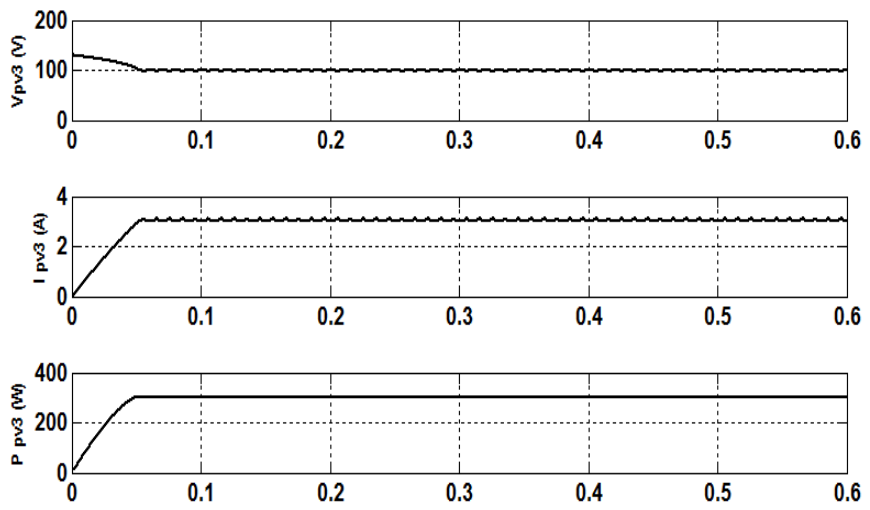

Fig.10. Simulation waveforms of the PV Panel 3

Voltage (V), Current (A), and Power (W).

The input parameters of the seven level cascaded multilevel inverter is taken as the three PV sources with each of 100 volts as the PV voltages and power as 300 watts each. The output voltage obtained by the seven level cascaded multi level inverter is three stepped wave form with the peak of 300 volts. The inverter connected to grid and the grid current is nearly 10 amperes, coming to the leakage current the frequency of common mode voltage is reduced by the sinusoidal pulse width modulation technique and if frequency of the common mode voltage reduced then the leakage current reduced. The leakage current of the seven level cascaded multi level inverter is below the $0.1 \mathrm{amp}$ i.e. $0.08 \mathrm{amps}$. The THD of the seven level multi level inverter is $0.07 \%$.
In the case of the leakage current minimization of seven level inverter, there is a variation in the common mode voltage but it is in the constant range of variation i.e. it is in between 100 and 200. The leakage current will appear in the variation in the common mode voltage.
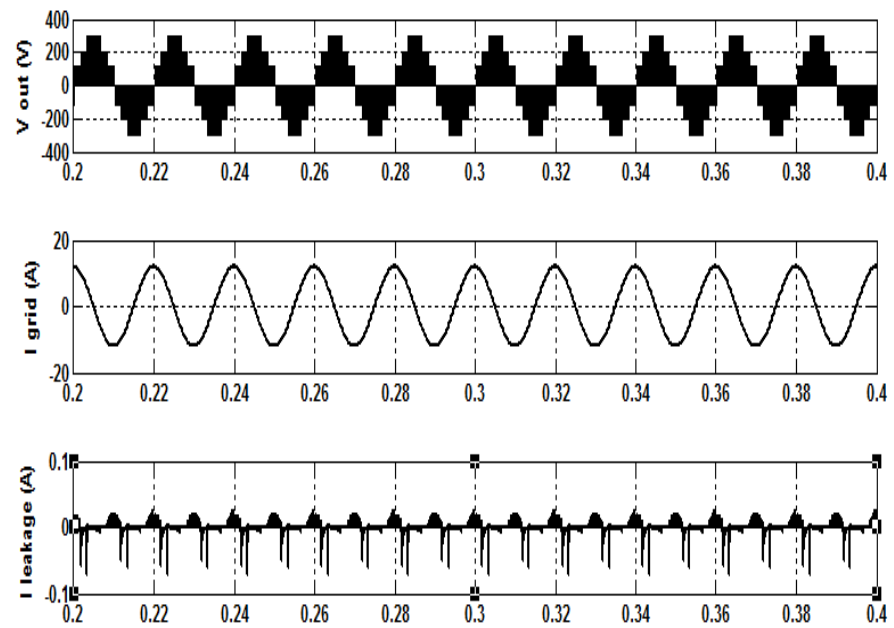

Fig 11. Simulation waveforms of the seven level CMLI Output Voltage (V), Grid Current (A) and Leakage Current (A).

Coming to the minimization of leakage current in the seven level inverter is achieve by the common mode voltage to constant value. The common mode voltage waveform is shown in the below figure 12 .

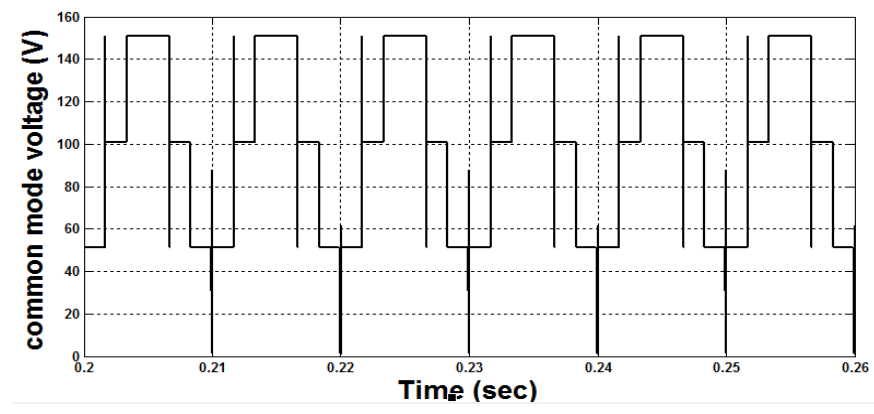

Fig 12. The common mode voltage of the cascaded seven level inverter. 


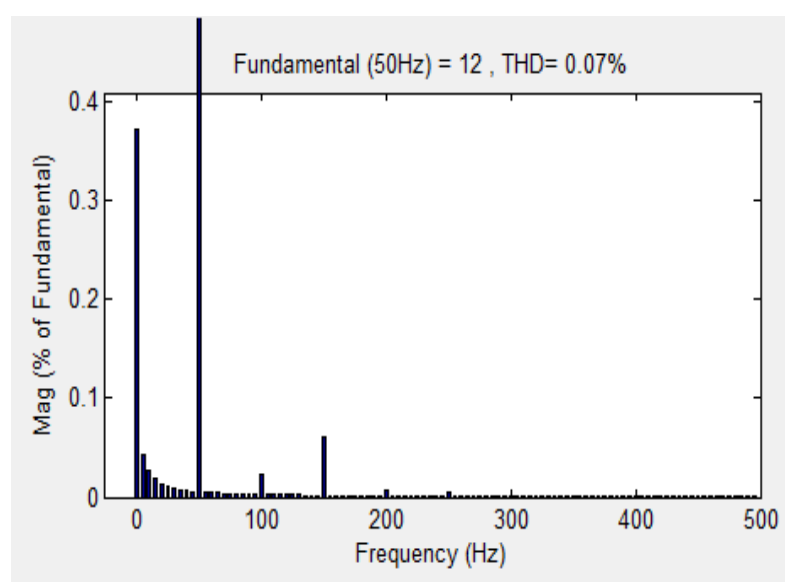

Fig 13. Total Harmonic Distortion of seven level inverter Output Current in \%

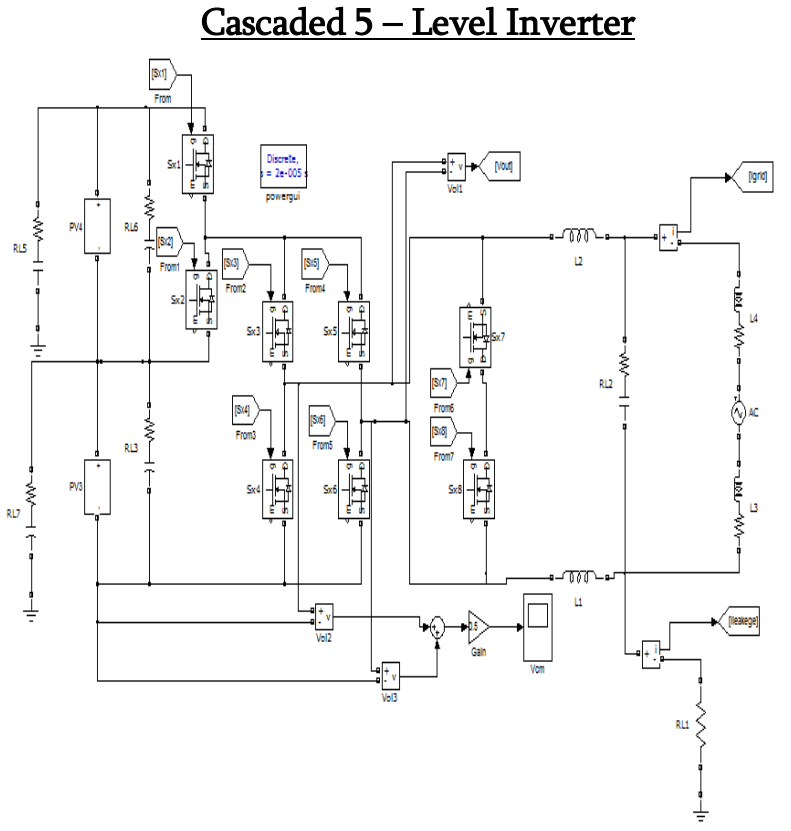

Fig 14 : MATLAB Model of Photovoltaic based 5level Cascaded MLI with reduced no. of switches.

The input parameters of the five level cascaded multilevel inverter is taken as the three PV sources with each of 200 volts as the PV voltages and power as 1000 watts each. The output voltage obtained by the five level cascaded multi level inverter is three stepped wave form with the peak of 400 volts. The inverter connected to grid and the grid current is nearly 5 amperes, coming to the leakage current the frequency of common mode voltage is reduced by the sinusoidal pulse width modulation technique and if frequency of the common mode voltage reduced then the leakage current reduced. The leakage current of the five level cascaded multi level inverter is 0.15 amps. The THD of the five level cascaded multi level inverter is $1.29 \%$.

In the case of the leakage current minimization of five level inverter, there is a variation in the common mode voltage but it is in the constant range of variation i.e. it is in between 100 and 200. The leakage current will appear in the variation in the common mode voltage.
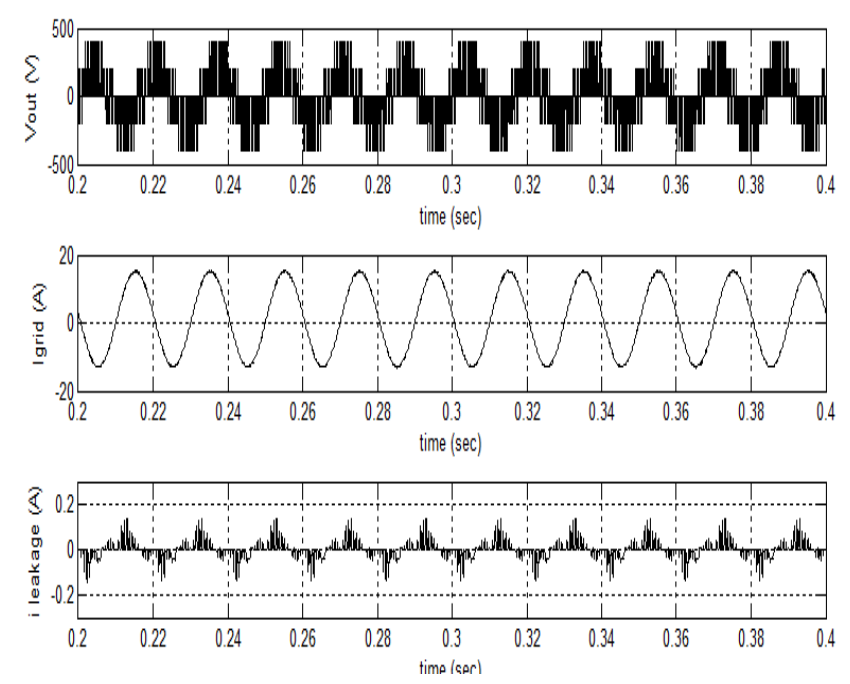

Fig 15. Simulation waveforms of the Five level CMLI Output Voltage (V), Grid Current (A) and Leakage Current (A).

Coming to the minimization of leakage current in the cascaded five level inverter is achieve by the common mode voltage to constant value. The common mode voltage waveform is shown in the below figure 16 .

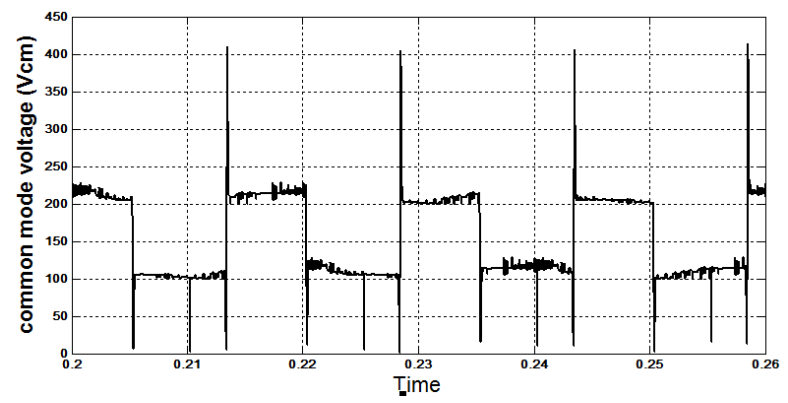

Fig 16. The common mode voltage of the cascaded five level inverter. 


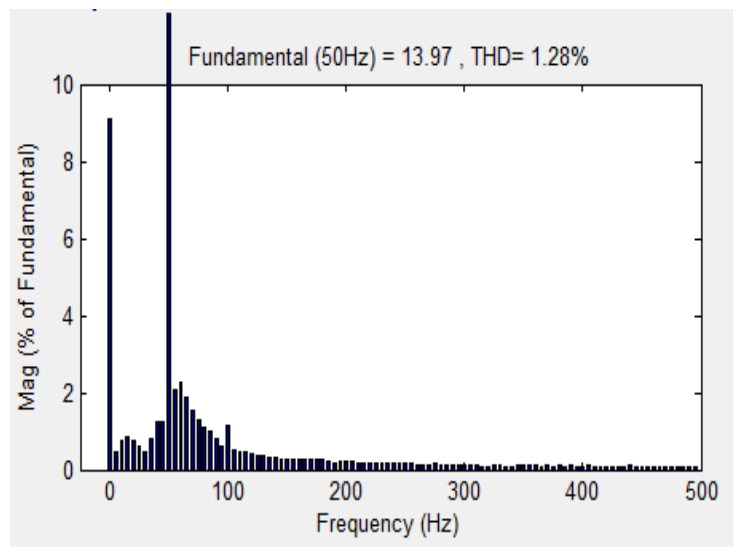

Fig 17. Total Harmonic Distortion of five level inverter Output Current in \%

\section{Three level inverter}

The input parameters of the three level inverter is taken as the three PV sources with each of 100 volts as the PV voltages and power as 300 watts each. The output voltage obtained by the three level inverter is one stepped wave form with the peak of 100 volts.

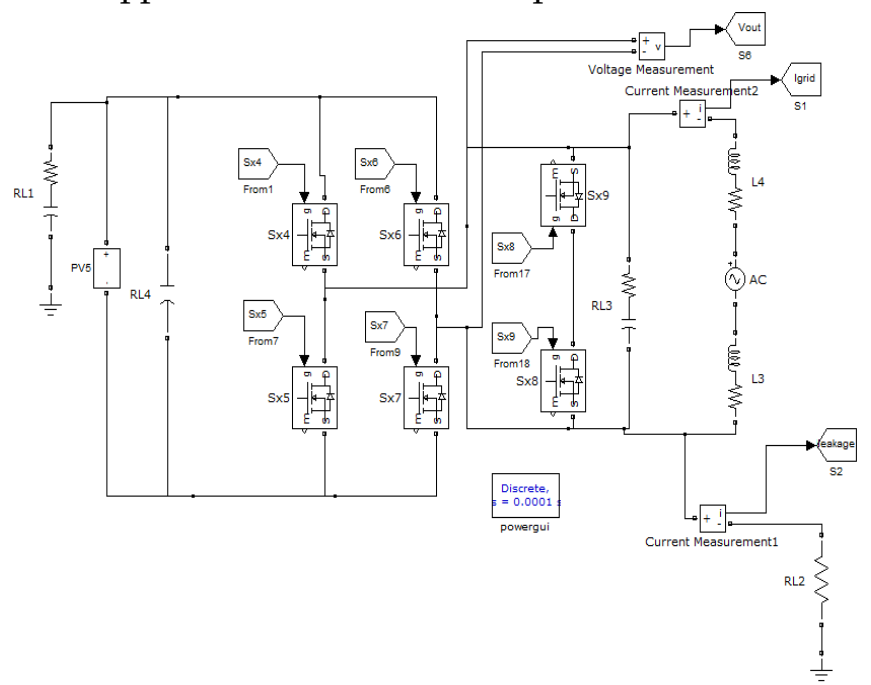

Fig 18. MATLAB Model of Photovoltaic based 3level Cascaded MLI with reduced no. of switches

The inverter connected to grid and the grid current is nearly 3 amperes, coming to the leakage current the frequency of common mode voltage is reduced by the sinusoidal pulse width modulation technique and if frequency of the common mode voltage reduced then the leakage current reduced. The leakage current of the three level inverter is below the 5 amps. The THD of the three level inverter is $7.02 \%$.
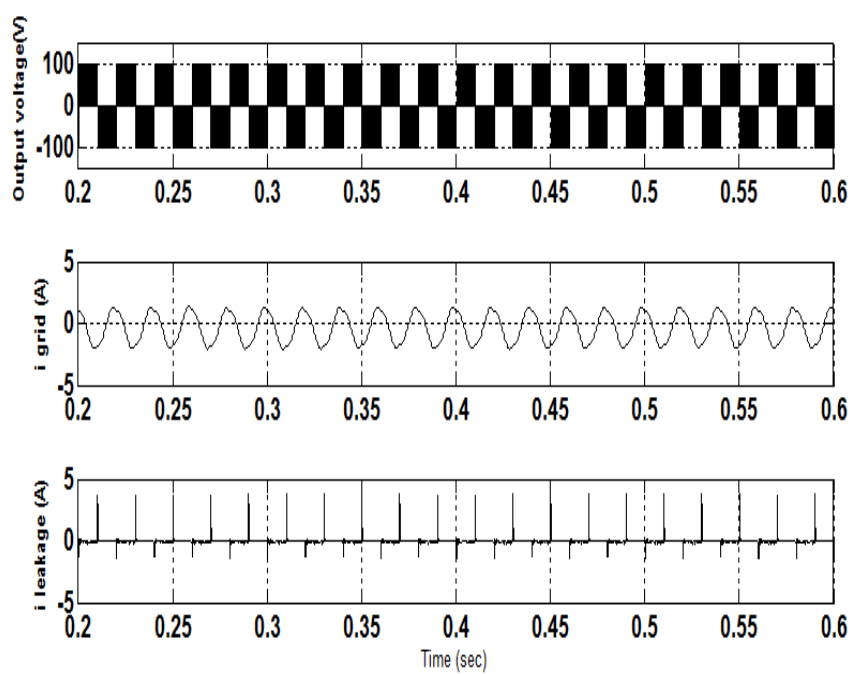

Fig 19. Simulation waveforms of the three level CMLI Output Voltage (V), Grid Current (A) and Leakage Current (A).

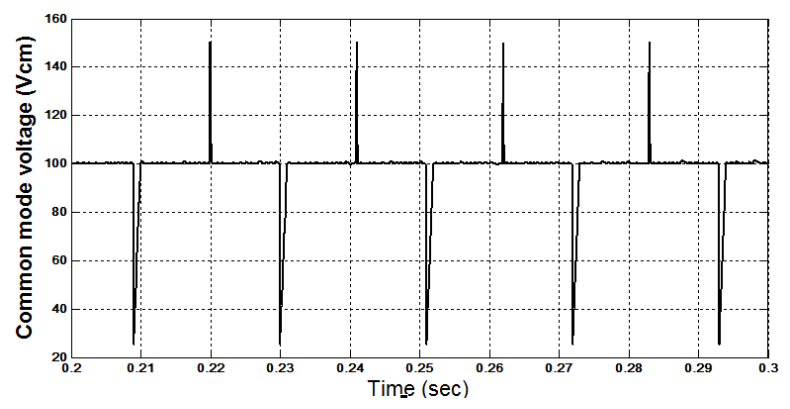

Fig 20. The common mode voltage of the cascaded three level inverter.

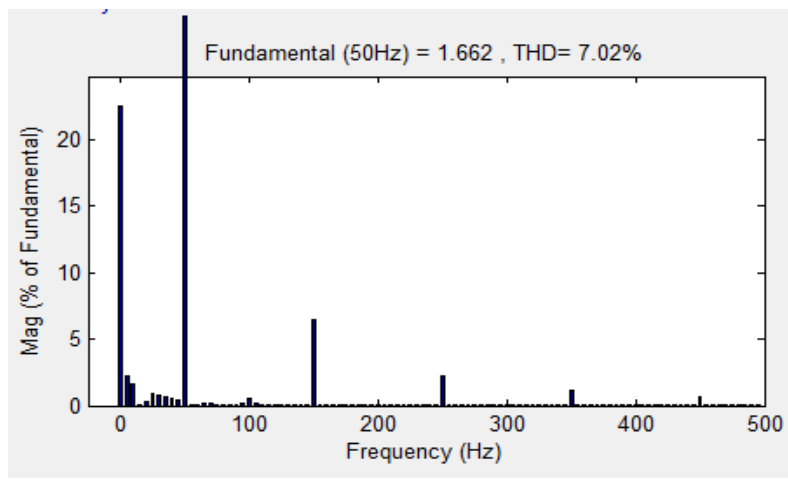

Fig 21. Total Harmonic Distortion of three level inverter Output Current in \% 


\section{CONCLUSION}

Photovoltaic based applications are increasing day by day. Since most of the electrical application are in AC, so some efficient Power Electronics DC to AC converters are required for converting photovoltaic DC output to AC. The proposed system having a Photovoltaic application based Cascaded 7- level Inverter has been shown to produce an increased stepped output with less number of semiconductor switches, and due to which controlling the overall circuit becomes less complex, the size and installation area reduced. Also included comparison of leakage currents and THD's of the 7-level,5-level and 3-level inverters using MATLAB/SIMULINK. It is inferred with the help of simulation results the Multicarrier PWM techniques produced a lower THD.

\section{REFERENCES}

[1]. Prof. Y Tang, W. Yao, P.C. Loh and F. Blaabjerg, "Highly Reliable Transformerless Photovoltaic Inverters With Leakage Current and Pulsating Power Elimination," IEEE Trans. Ind. Elect., vol. 63, no. 2, pp. 1016-1026, Feb. 2016.

[2]. W Li, Y. Gu, H. Luo, W. Cui, X. He and C. Xia, "Topology Review and Derivation Methodology of Single-Phase Transformerless Photovoltaic Inverters for Leakage Current Suppression," IEEE Trans. Ind. Elect., vol. 62, no. 7, pp. 45374551, July 2015.

[3]. J Ji, W. Wu, Y. He, Z. Lin, F. Blaabjerg and H. S. H. Chung, "A Simple Differential Mode EMI Suppressor for the LLCL-Filter-Based SinglePhase Grid-Tied Transformerless Inverter," IEEE Trans. Ind. Elect., vol. 62, no. 7, pp. 41414147, July 2015

[4]. Y Bae and R.Y.Kim, "Suppression of CommonMode Voltage Using a Multicentral Photovoltaic Inverter Topology With
Synchronized PWM," IEEE Trans. Ind. Elect., vol. 61, no. 9, pp. 4722-4733, Sept. 2014.

[5]. N Vazquez, M. Rosas, C. Hernandez, E. Vazquez and F. J. Perez-Pinal, "A New Common-Mode Transformerless Photovoltaic Inverter," IEEE Trans. Ind. Elect., vol. 62, no. 10, pp. 6381-6391, Oct. 2015.

[6]. G Buticchi, E. Lorenzani and G. Franceschini, "A Five-Level Single-Phase Grid-Connected Converter for Renewable Distributed Systems," IEEE Trans. Ind. Elect., vol.60, no.3, pp.906918, March 2013.

[7]. NA. Rahim and J. Selvaraj, "Multistring FiveLevel Inverter With Novel PWM Control Scheme for PV Application," IEEE Trans. Ind. Elect., vol.57, no.6, pp.2111-2123, June 2010.

[8]. M Cavalcanti, K. De Oliveira, A. M. de Farias, F. Neves, G. Azevedo and F. Camboim, "Modulation Techniques to Eliminate Leakage Currents in Transformerless Three-Phase Photovoltaic Systems," IEEE Trans. Ind. Elect., vol. 57, no. 4, pp. 1360-1368, April 2010.

[9]. L Zhang, K. Sun, L. Feng, H. Wu and Y. Xing, "A Family of Neutral Point Clamped FullBridge Topologies for Transformerless Photovoltaic Grid-Tied Inverters," IEEE Trans. Power Elect., vol.28, no.2, pp.730-739, Feb. 2013.

[10]. M. Islam and S. Mekhilef, "H6-type transformerless single-phase inverter for gridtied photovoltaic system," IET Elect. Power Elect., vol.8, no.4, pp.636-644, 2015.

[11]. H.F. Xiao, K. Lan and L. Zhang, "A QuasiUnipolar SPWM Full-Bridge Transformerless PV Grid-Connected Inverter with Constant Common-Mode Voltage," IEEE Trans. Power Elect., vol.30, no.6, pp.3122-3132, June 2015.

[12]. B.Ji, J. Wang and J. Zhao, "High-Efficiency Single-Phase Transformerless PV H6 Inverter With Hybrid Modulation Method," IEEE Trans. Ind. Elect., vol.60, no.5, pp.2104-2115, May 2013. 
[13]. G. Buticchi, D. Barater, E. Lorenzani, C. Concari and G. Franceschini, "A Nine-Level Grid-Connected Converter Topology for Single-Phase Transformerless PV Systems," IEEE Trans. Ind. Elect., vol.61, no.8, pp.39513960, Aug. 2014.

[14]. F. Hong, J. Liu, B. Ji, Y. Zhou, J. Wang and C. Wang, "Single Inductor Dual Buck Full-Bridge Inverter," IEEE Trans. Ind. Elect., vol.62, no.8, pp.4869-4877, Aug. 2015.

[15]. S. V. Araujo, P. Zacharias and R. Mallwitz, "Highly Efficient Single-Phase Transformerless Inverters for Grid-Connected Photovoltaic Systems," IEEE Trans. Ind. Elect., vol. 57, no. 9, pp. 3118-3128, Sept. 2010.

[16]. O. Lopez, R. Teodorescu and J. D. Gandoy, "Multilevel transformerless topologies for single-phase grid-connected converters," APEC 2006, pp.5191-5196, Nov. 2006.

[17]. O. Lopez, R. Teodorescu, F. Freijedo and J.D. Gandoy, "Leakage current evaluation of a single-phase Transformerless PV inverter connected to the grid," APEC 2007, pp.907-912, March 2007.

[18]. O. Lopez, F.D. Freijedo, A.G. Yepes, P. F. Comesaa, J. Malvar, R. Teodorescu and J. D. Gandoy, "Eliminating Ground Current in a Transformerless Photovoltaic Application," IEEE Trans. Energy Conv., vol.25, no.1, pp.140147, March 2010.

[19]. G. Vazquez, P.R.M. Rodriguez, G. Escobar, J.M. Sosa and R.M. Mendez, "A PWM method for single-phase cascade multilevel inverters to reduce leakage ground current in transformerless PV systems," (accepted for publication in International Transactions on Electrical Energy Systems, Wiley Publications).
Cite this article as : Naveen Kokku, "Grid Interconnecting Solar Generation System Using Transformer Less Cascaded Seven Level Inverter", International Journal of Scientific Research in Science and Technology (IJSRST), Online ISSN : 2395-602X, Print ISSN : 2395-6011, Volume 6 Issue 1, pp. 235-245, January-February 2019. Available at doi : https://doi.org/10.32628/IJSRST196132 Journal URL : http://ijsrst.com/IJSRST196132 